\title{
Contribution of mammography to MRI screening in BRCA mutation carriers by BRCA status and age: individual patient data meta-analysis
}

Xuan-Anh Phi ${ }^{*}, 1$, Sepideh Saadatmand ${ }^{2}$, Geertruida H De Bock ${ }^{1}$, Ellen Warner ${ }^{3}$, Francesco Sardanelli ${ }^{4}$, Martin O Leach ${ }^{5}$, Christopher C Riedl' ${ }^{6}$, Isabelle Trop ${ }^{7}$, Maartje J Hooning ${ }^{8}$, Rodica Mandel ${ }^{3}$, Filippo Santoro 9 , Gek Kwan-Lim ${ }^{5}$, Thomas H Helbich ${ }^{6}$, Madeleine MA Tilanus-Linthorst ${ }^{10}$, Edwin R van den Heuvel ${ }^{11}$ and Nehmat Houssami ${ }^{12}$

'Department of Epidemiology, University of Groningen, University Medical Center Groningen, Postbus 30 001, 9700RB Groningen, The Netherlands;
2Department of Surgical Oncology, Erasmus University Medical Center Rotterdam, Groene Hilledijk 301, 3075EA Rotterdam, The Netherlands;
${ }^{3}$ Department of Medicine, Division of Medical Oncology, Sunnybrook Health Sciences Centre, University of Toronto, 2075 Bayview Avenua, Toronto,
ON, Canada M4N 3M5; ${ }^{4}$ On behalf of the HIBCRIT-1 Study, Department of Biomedical Sciences for Health, University of Milan School of Medicine,
Scientific Institute (IRCCS) Policlinico San Donato, Unit of Radiology, Via Morandi 30, San Donato Milanese, Milan 20097 , Italy; ${ }^{5}$ On behalf of the MARIBS
Study, CRUK Cancer Imaging Centre at The Institute of Cancer Research and The Royal Marsden NHS Foundation Trust, 123 Old Brompton Road,
London SW7 3RP, UK; ${ }^{6}$ Department of Biomedical Imaging and Image-guided Therapy, Division of Molecular and Gender Imaging, Medical University
Vienna, Spitalgasse 23 Vienna 1090, Austria; ${ }^{7}$ Department of Radiology, Breast Imaging Division, Centre Hospitalier of the University of Montreal (CHUM),
Montreal, Tour viger, Pavillion R, 900 Saint Denis Street, Montreal, QC, Canada H2X OA9; ${ }^{8}$ Department of Medical Oncology, Family Cancer Clinic,
Erasmus MC Cancer Institute, Groene Hilledijk 301, 3075EA Rotterdam, The Netherlands; ${ }^{9}$ On behalf of the HIBCRIT-1 Study, Department of Cell Biology
and Neurosciences, Istituto Superiore di Sanità, Viale Regina Elena 299, 00161 Rome, Italy; ${ }^{10}$ On behalf of MRISC Study, Department of Surgical
Oncology, Erasmus University Medical Center Rotterdam, Groene Hilledijk 301, 3075EA Rotterdam, The Netherlands; ${ }^{11}$ Department of Mathematics and
Computer Science, Eindhoven University of Technology, Den Dolech 2, 5600 MB Eindhoven, The Netherlands and ${ }^{12}$ Screening and Test Evaluation
Program (STEP), School of Public Health, Sydney Medical School, The University of Sydney, Edward Ford Building (A27), Sydney, NSW 2006, Australia

Background: We investigated the additional contribution of mammography to screening accuracy in BRCA1/2 mutation carriers screened with MRI at different ages using individual patient data from six high-risk screening trials.

Methods: Sensitivity and specificity of MRI, mammography and the combination of these tests were compared stratified for BRCA mutation and age using generalised linear mixed models with random effect for studies. Number of screens needed (NSN) for additional mammography-only detected cancer was estimated.

Results: In BRCA1/2 mutation carriers of all ages (BRCA1 $=1219$ and $B R C A 2=732$ ), adding mammography to MRI did not significantly increase screening sensitivity (increased by $3.9 \%$ in BRCA1 and $12.6 \%$ in BRCA2 mutation carriers, $P>0.05$ ). However, in women with BRCA2 mutation younger than 40 years, one-third of breast cancers were detected by mammography only. Number of screens needed for mammography to detect one breast cancer not detected by MRI was much higher for BRCA1 compared with BRCA2 mutation carriers at initial and repeat screening.

Conclusions: Additional screening sensitivity from mammography above that from MRI is limited in BRCA1 mutation carriers, whereas mammography contributes to screening sensitivity in BRCA2 mutation carriers, especially those $\leqslant 40$ years. The evidence from our work highlights that a differential screening schedule by BRCA status is worth considering.

*Correspondence: X-A Phi; E-mail: x.a.phi@umcg.nl

Received 24 July 2015; revised 17 December 2015; accepted 25 January 2016; published online 23 February 2016

(c) 2016 Cancer Research UK. All rights reserved 0007-0920/16 
Women with a $B R C A 1$ or $B R C A 2$ mutation have limited choices to prevent mortality resulting from their $40-80 \%$ lifetime risk for breast cancer (Chen and Parmigiani, 2007). Screening with yearly MRI from age 25 years onwards, and additional mammography from age 30 years is recommended in international guidelines (Mann et al, 2008; Sardanelli et al, 2010; Zonderland et al, 2012; NICE, 2013), and is estimated to be slightly less effective than preventive mastectomy (Kurian et al, 2010; Heemskerk-Gerritsen et al, 2013). Several prospective high-risk screening studies have evaluated both MRI and mammography (Lord et al, 2007; Warner et al, 2008) as a screening strategy in high-risk women to improve screening sensitivity. In the absence of randomised controlled trials for MRI screening, these screening studies build on evidence that early detection of breast cancer may confer benefit as shown for mammography in population screening (Glasziou and Houssami, 2011). The combination of mammography and MRI screening of $B R C A 1 / 2$ carriers in most guidelines, from the age of 30 or 40 years (Mann et al, 2008; Sardanelli et al, 2010; Zonderland et al, 2012; NICE, 2013), is based on the enhanced sensitivity shown through this strategy (Lord et al, 2007; Warner et al, 2008), despite arguments around limitations of mammography. These include that mammography is relatively sensitive in fatty breasts (generally in older women) but less sensitive in young women who frequently have dense breasts. In addition, screening with mammography could lead to the induction of breast cancer by X-rays at younger ages (Jansen-van der Weide et al, 2010). Proper repair of DNA double-strand breaks that are caused by low-dose X-rays is impaired at any age in both BRCA1 and BRCA2 mutations carriers (Powell and Kachnic, 2003). This makes BRCA1 and BRCA2 mutation carriers more susceptible than non-carriers, possibly also at older ages, to the cumulative effect of yearly mammograms. Given these potential disadvantages of mammography, it is important to balance the potential benefits and harms of mammography screening in BRCA1/2 mutation carriers. Hence, substantial early detection of breast cancer by mammography is needed to outweigh the potential harm of cancer induction (Jansen-van der Weide et al, 2010) in BRCA1/2 mutation carriers.

We performed an individual patient data (IPD) meta-analysis from six prospective MRI screening studies to determine if mammography screening in $B R C A 1 / 2$ mutation carriers in addition to MRI improves screening accuracy, and whether this effect differs between $B R C A 1$ and BRCA2 gene mutation carriers or by different age groups.

\section{MATERIALS AND METHODS}

An IPD meta-analysis was conducted by pooling individual data from relevant prospective MRI screening studies (Phi et al, 2014). Studies were eligible if mammography and MRI breast cancer sensitivity and specificity were compared in women with a BRCA1/ 2 mutation. After searching PubMed, 12 studies met the eligibility requirements and were sought to contribute to the data (Phi et al, 2014). Six of these provided IPD data (Leach et al, 2005; Rijnsburger et al, 2010; Trop et al, 2010; Sardanelli et al, 2011; Passaperuma et al, 2012; Riedl et al, 2015), and were included in this meta-analysis; the reasons for non-inclusion of some studies have been reported in our earlier work (Phi et al, 2014). Included studies were assessed in terms of reporting quality, and were qualified as high quality (Phi et al, 2014). The data were assembled and cross-checked with the original publications; inclusion criteria for analyses were women with a BRCA1/2 mutation, screened annually with both mammography and MRI. Breast cancer diagnosis was confirmed by pathology and the absence of breast cancer at 1 year follow-up (Phi et al, 2014). A summary of the included studies was reported previously (http://jco.ascopubs.org/ content/33/4/349/T1.large.jpg)
Primary outcome and definition. Primary outcome was sensitivity and specificity of mammography and MRI separately, as well as combined. Analyses were stratified for mutation type (BRCA1 or $B R C A 2$ ) and age in years at screening (40 years and younger, between 41 and 50 years, over 50 years).

Sensitivity was defined as the number of breast cancers detected by a screening modality (MRI or mammography, or the combination) from the total number of breast cancers diagnosed during the study course. Specificity of a screening modality was defined as the number classified as true negative by the test from the total number of true-negative plus false-positive results.

A true positive was defined as a positive screening result (BI-RADS $0,3,4,5)$ followed by a pathology-proven breast cancer. A false positive was defined as a positive screening result (BI-RADS $0,3,4,5)$ not followed by a pathology-proven breast cancer within 1 year of follow-up. A true negative was defined as a negative screening result (BI-RADS 1,2) not followed by pathology-proven breast cancer within 1 year of follow-up. A false-negative case was defined as a negative screening result (BI-RADS 1,2$)$ followed by a pathology-proven breast cancer within 1 year of follow-up.

Statistical analysis. Stratified by BRCA status and age group, descriptive statistics of the characteristics of the women and their breast cancer were provided. Breast cancer incidence was calculated per 1000 woman-years. The related 95\% confidence intervals (CIs) were computed, assuming the incidence follows a Poisson distribution. To compare differences between groups in proportion of DCIS, invasive tumour size and grade, $\chi^{2}$ tests or Fisher's exact tests were applied.

To estimate the sensitivity and the specificity of the screening modalities, repeated screening results were summarised to form binomial counts for each woman. For each woman, the number of true-positive and true-negative screens per modality, and the number of total screening visits with or without breast cancer detected were counted. In this way, binomial counts per modality were calculated and analysed, taking into account that each woman was her own control. As the dependent variable was assumed to follow a binomial distribution, a generalised linear mixed model with logit link function was applied, and the binomial proportions were modelled as a function of modality and BRCA status and conducted separately for sensitivity and specificity. Studies were entered as random-effect variables and study heterogeneities were assumed to depend on modality. The analyses were conducted separately for each age group. To test the differences between the sensitivities and specificities for the three modalities, Wald tests were applied, where the hypothesis was that the difference between the two proportions under study was 0 .

The number of mammographic screens that would have been needed (NSN) to detect one breast cancer that was missed by MRI was calculated, and stratified according to BRCA mutation, age group and screening round (first or subsequent round). All analyses were performed using SAS 9.4 (SAS Institute, Cary, NC, USA). $P$-values $<0.05$ were considered statistically significant.

\section{RESULTS}

Study population and breast cancer characteristic. The analyses were based on 1951 BRCA1/2 mutation carriers with 6085 womanyears of follow-up (Table 1). There was no significant difference in cancer risk between $B R C A 1$ and $B R C A 2$ mutation carriers.

Five breast cancers were diagnosed before the age of 30 in BRCA1 mutation carriers, and none in BRCA2 mutation carriers. The proportion of DCIS differed between BRCA groups in age groups older than 40 years, as shown in Table 1.

Sensitivity and specificity of MRI and mammography in BRCA1 mutation carriers. In $B R C A 1$ mutation carriers, there were no 
Table 1. Overview of women $(n=1951)$ and their BCs $(n=184)^{a}$

\begin{tabular}{|c|c|c|c|c|c|c|c|c|}
\hline & \multicolumn{2}{|c|}{ All ages } & \multicolumn{2}{|c|}{ Age $\leqslant 40$ years } & \multicolumn{2}{|c|}{ Age $41-50$ years } & \multicolumn{2}{|c|}{ Age over 50 years } \\
\hline Women $(N)$ & 1219 & 732 & 605 & 301 & 482 & 308 & 310 & 228 \\
\hline $\mathrm{BC}(N)$ & 112 & 72 & 46 & 18 & 38 & 37 & 28 & 17 \\
\hline $\mathrm{BC}$ risk $((95 \% \mathrm{Cl})$ & $29.2(24-35.1)$ & $32.1(25.1-.40 .4)$ & $27.2(19.9-36.3)$ & $24(14.2-38)$ & $31.3(22.1-42.9)$ & $45.6(32.1-62.8)$ & $31.3(20.8-45.2)$ & $25.3(14.7-40.4)$ \\
\hline Invasive cancers $^{c}$ & 97 (86.6\%) & 50 (69.4\%) & $37(80.4 \%)$ & 15 (83.3\%) & 35 (92.1\%) & $24(64.9 \%)$ & 25 (89.3\%) & $11(64.7 \%)$ \\
\hline Invasive $<1 \mathrm{~cm}$ & $26(26.8 \%)$ & 17 (34.0\%) & $8(21.6 \%)$ & $2(13.3 \%)$ & $10(28.6 \%)$ & $11(45.8 \%)$ & $8(32.0 \%)$ & $4(36.4 \%)$ \\
\hline Invasive $1-2 \mathrm{~cm}$ & $35(36.1 \%)$ & $12(24.0 \%)$ & $13(35.1 \%)$ & $5(33.3 \%)$ & 8 (22.9\%) & $3(12.5 \%)$ & 14 (56.0\%) & $4(36.4 \%)$ \\
\hline Grade 1 & $7(7.2 \%)$ & $5(10.0 \%)$ & $1(2.7 \%)$ & $0(-)$ & $4(11.4 \%)$ & $3(12.5 \%)$ & $2(8.0 \%)$ & 2 (18.2\%) \\
\hline $\begin{array}{l}\text { Early-stage } \\
\text { tumour } \\
\text { (DCIS or invasive } \\
<1 \mathrm{~cm})\end{array}$ & $41(36.6 \%)$ & 39 (54.2\%) & $17(37.0 \%)$ & $5(27.8 \%)$ & $13(34.2 \%)$ & $24(64.9 \%)$ & $11(39.3 \%)$ & $10(58.8 \%)$ \\
\hline
\end{tabular}

Table 2. Sensitivity and specificity of screening modalities ${ }^{2}$

\begin{tabular}{|c|c|c|c|c|c|c|c|c|c|c|}
\hline \multirow[b]{2}{*}{$\begin{array}{l}\text { Age } \\
\text { group } \\
\text { (years) }\end{array}$} & \multirow[b]{2}{*}{$\begin{array}{c}\text { Mutation } \\
\text { status }\end{array}$} & \multicolumn{3}{|c|}{ Mammography } & \multicolumn{3}{|c|}{ MRI } & \multicolumn{3}{|c|}{ Combination } \\
\hline & & $\begin{array}{c}\text { No. } \\
\text { of } B C \\
\text { detected }\end{array}$ & $\begin{array}{c}\text { Sensitivity } \\
(\%) \\
(95 \% \mathrm{Cl})\end{array}$ & $\begin{array}{c}\text { Specificity } \\
(\%) \\
(95 \% \mathrm{Cl})\end{array}$ & $\begin{array}{c}\text { No. } \\
\text { of BC } \\
\text { detected }\end{array}$ & $\begin{array}{c}\text { Sensitivity } \\
(\%) \\
(95 \% \mathrm{Cl})\end{array}$ & $\begin{array}{c}\text { Specificity } \\
(\%) \\
(95 \% \mathrm{Cl})\end{array}$ & $\begin{array}{c}\text { No. } \\
\text { of BC } \\
\text { detected }\end{array}$ & $\begin{array}{c}\text { Sensitivity } \\
(\%) \\
(95 \% \mathrm{Cl})\end{array}$ & $\begin{array}{c}\text { Specificity } \\
(\%) \\
(95 \% \mathrm{Cl})\end{array}$ \\
\hline \multirow{2}{*}{ All ages } & BRCA1 $(\mathrm{n}=112)$ & 39 & 35.7 (25.9-46.9) & $93.8(89.3-96.5)$ & 92 & $88.6(73.4-95.6)$ & $84.4(78.7-88.8)$ & 98 & $92.5(80.1-97.4)$ & $80.4(72.8-86.2)$ \\
\hline & BRCA2 $(n=72)$ & 31 & $44.6(31.9-58)$ & $93.4(88.4-96.3)$ & 53 & $80.1(58.9-91.9)$ & $85.3(79.6-89.6)$ & 64 & $92.7(79.3-97.7)$ & $80.5(72.8-86.4)$ \\
\hline \multirow{2}{*}{$\leqslant 40$} & $B R C A 1(n=46)$ & 18 & $39.1(26.2-53.9)$ & $94.9(91.2-97.1)$ & 34 & 77.5 (57-90) & $84.3(78.7-88.7)$ & 38 & $86.8(63.1-96.2)$ & 81 (73.9-86.5) \\
\hline & $B R C A 2(n=18)$ & 10 & $55.6(32.9-76.1)$ & $92.3(86.6-95.7)$ & 9 & $52.7(27.2-76.8)$ & $80.2(72.9-85.8)$ & 15 & $87.2(56.1-97.3)$ & $75.3(66.6-82.4)$ \\
\hline \multirow{2}{*}{$41-50$} & $B R C A 1(\mathrm{n}=38)$ & 13 & $34.2(21-50.5)$ & $91.5(86.7-94.6)$ & 34 & 93.1 (70.8-98.7) & 82.9 (77.9-87) & 35 & $94.1(74.5-98.9)$ & $77.2(70.5-82.8)$ \\
\hline & $B R C A 2(n=38)$ & 14 & $37.8(22.7-55.5)$ & $92(87-95.2)$ & 30 & $86.4(58.2-96.7)$ & $86(81.1-89.8)$ & 33 & $91.2(70.4-97.9)$ & $80(73.3-85.3)$ \\
\hline \multirow{2}{*}{$>50$} & BRCA1 $(n=28)$ & 8 & $29.4(12.8-54.2)$ & $96.8(91.9-98.8)$ & 24 & $89.1(54.8-98.2)$ & $89.9(82.6-94.3)$ & 25 & $89.3(71.3-96.6)$ & $87.4(79.3-92.6)$ \\
\hline & $B R C A 2(n=17)$ & 7 & $45.5(19.3-74.4)$ & $97.4(92.8-99.1)$ & 14 & 85 (43.7-97.7) & $91.1(84-95.2)$ & 16 & 94.1 (67.5-99.2) & $88.6(80.7-93.6)$ \\
\hline
\end{tabular}

statistically significant differences in sensitivity and specificity between mammography and MRI combined compared with MRI alone. Sensitivity of the combination was higher compared with that of MRI alone in all age groups (age $\leqslant 40: 86.8 \%(63.1-96.2) v s$ 77.5\% (57-90), $P=0.441$; age 41-50: $94.1 \%$ (74.5-98.9) vs $93.1 \%$ (70.8-98.7), $P=0.895$; age $>50: 89.3 \%$ (71.3-96.6) vs $89.1 \%(54.8-$ 98.2), $P=0.986)$. Combining mammography and MRI decreased specificity compared with MRI screening alone in all age groups (age $\leqslant 40$ years: $81 \%(73.9-86.5)$ vs $84.3 \%$ (78.7-88.7), $P=0.409$; age $41-50$ years: $77.2 \%(70.5-82.8)$ vs $82.9 \%(77.9-87), P=0.135$; age $>50$ years: $87.4 \%(79.3-92.6)$ vs $89.9 \%$ (82.6-94.3), $P=0.566)$. Further results are shown in Table 2.

Sensitivity and specificity of MRI and mammography in BRCA2 mutation carriers. In $B R C A 2$ carriers, there were no significant differences in sensitivity or specificity between combined mammography and MRI and MRI alone in all age groups. Sensitivity of the combination was higher compared with that of MRI alone in all age groups (age $\leqslant 40$ years: $87.2 \%(56.1-97.3)$ vs $52.7 \%(27.2-$ 76.8), $P=0.075$; age $41-50$ years: $91.2 \%$ (70.4-97.9) vs $86.4 \%$ (58.2-96.7), $P=0.646$; age $>50$ years: $94.1 \%$ (67.5-99.2) vs $85 \%$
(43.7-97.7), $P=0.474)$. Combining mammography and MRI decreased specificity compared with MRI screening alone in all age groups (age $\leqslant 40$ years: $75.3 \% \quad(66.6-82.4)$ vs $80.2 \%$ (72.9-85.8), $P=0.351$; age $41-50$ years: $80 \%$ (73.3-85.3) vs $86 \%$ (81.1-89.8), $P=0.105$; age $>50$ years: $88.6 \%$ (80.7-93.6) vs $91.1 \%$ (84-95.2), $P=0.565)$. Further results are shown in Table 2.

Mammography contribution to screening sensitivity in $B R C A 1$ mutation carriers. In BRCA1 carriers overall, adding mammography to MRI screening increased sensitivity by roughly $4-92.5 \%$ (Table 2) $(P=0.553)$. In the $\leqslant 40$ years age group, the addition of mammography increased sensitivity by $9.3 \%$ (Table 2 ). Without mammography, 3 of $46(6.5 \%)$ breast cancers, including 2 DCIS, would not have been detected (Table 3 ) in this subgroup. In the 41-50 years group, additional mammography increased sensitivity by only $1 \%$ (Table 2 ), detecting 1 DCIS (2.7\%) (Table 3 ). Similarly, in the $>50$ years age group, mammography detected one additional cancer (3.4\% of cancers) (Table 3 ).

Mammography contribution to screening sensitivity in $B R C A 2$ mutation carriers. In $B R C A 2$ carriers, adding mammography to 
Table 3. Mammography-only detected breast cancers stratified for BRCA1 or BRCA2 mutation status

\begin{tabular}{|c|c|c|c|c|c|c|}
\hline No. & Mutation status & Age at diagnosis & Tumour type & Invasive tumour size & Invasive tumour grade & Screening round \\
\hline 1 & BRCA1 & 31 & DCIS & - & - & 2 \\
\hline 2 & BRCA1 & 33 & DCIS & - & - & 2 \\
\hline 3 & BRCA1 & 40 & IDC & $1-2 \mathrm{~cm}$ & Grade 3 & 1 \\
\hline 4 & BRCA1 & 42 & $\mathrm{DClS}$ & - & - & 3 \\
\hline 5 & BRCA1 & 56 & IDC & $<1 \mathrm{~cm}$ & Grade 3 & 4 \\
\hline 1 & BRCA2 & 36 & DCIS & - & - & 1 \\
\hline 2 & BRCA2 & 37 & DCIS & - & - & 1 \\
\hline 3 & BRCA2 & 35 & IDC & $<1 \mathrm{~cm}$ & Grade 2 & 4 \\
\hline 4 & BRCA2 & 36 & IDC & $1-2 \mathrm{~cm}$ & Grade 3 & 1 \\
\hline 5 & BRCA2 & 37 & ILC & $2-5 \mathrm{~cm}$ & Grade 2 & 1 \\
\hline 6 & BRCA2 & 39 & Other & NA & NA & 3 \\
\hline 7 & BRCA2 & 42 & DCIS & - & - & 4 \\
\hline 8 & BRCA2 & 53 & DCIS & - & - & 2 \\
\hline 9 & BRCA2 & 44 & ILC & $>5 \mathrm{~cm}$ & 3 & 1 \\
\hline 10 & BRCA2 & 47 & ILC & $>5 \mathrm{~cm}$ & 2 & 5 \\
\hline 11 & BRCA2 & 51 & NA & NA & NA & 1 \\
\hline
\end{tabular}

\section{Table 4. NSN for one additional mammography-only detected cancer for first and subsequent screening rounds}

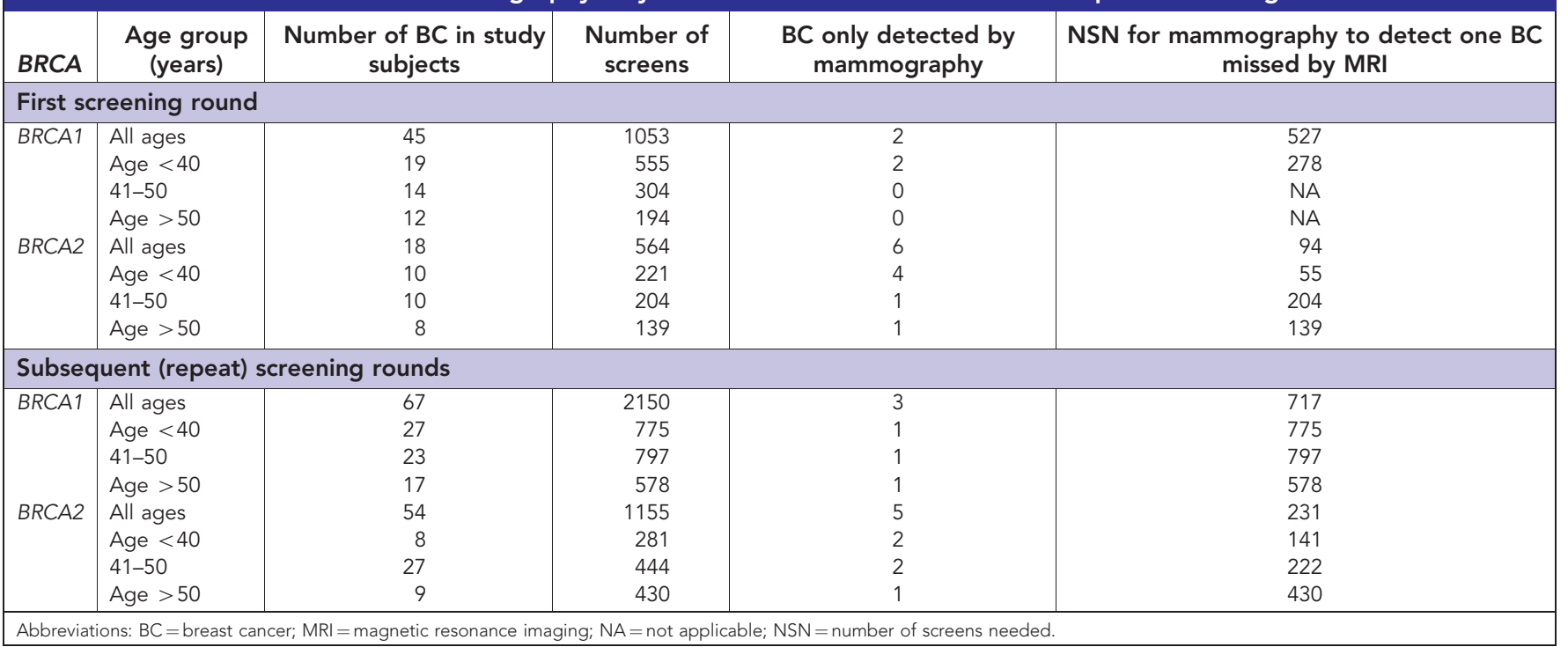

MRI screening increased sensitivity by $12.6-92.7 \%$ (Table 2) $(P=0.154)$. In the $\leqslant 40$ age group, additional mammography increased sensitivity by $34.5 \%$ (Table 2 ). Without mammography, 6 of 18 cancers $(33.3 \%)$, including 2 DCIS, would not have been detected in this young age group (Table 3 ). In women aged 41-50 years, adding mammography nonsignificantly increased sensitivity by nearly $5 \%$ (Table 2) and detected 3 cancers, including 1 DCIS, which were not detected by MRI ( $8.1 \%$ of cancers). In the $>50$ years age group, screening sensitivity increased nonsignificantly by $\sim 9 \%$ (Table 2), and mammography detected two cancers (11.8\%) that were not detected by MRI, including 1 DCIS.

Number of mammographic screens needed to detect one breast cancer not detected by MRI. For the first screening round, the NSN for mammography to detect one breast cancer not detected by MRI was 527 for women with a BRCA1 mutation and 94 for women with a BRCA2 mutation for all ages (Table 4). For subsequent screening rounds, the NSN for mammography to detect an additional breast cancer for women with a BRCA1 mutation (717 screens) was roughly three times that for women with a BRCA2 mutation (231 screens).

\section{DISCUSSION}

This IPD meta-analysis has identified differences in the contribution of mammography to screening high-risk women according to age and mutation status. Adding mammography to MRI screening in $B R C A 1$ mutation carriers leads to a very modest increase in sensitivity of $3.9 \%$ among 112 breast cancers $(P=0.553)$, and a small decrease in specificity (by $4 \%, P=0.154$ ). One invasive cancer and 2 DCIS (6.5\%) of the 46 BRCA1 breast cancers detected before the age of 40 years, and only 1 DCIS and 1 invasive cancer $<1 \mathrm{~cm}(3 \%)$ in a total of 66 BRCA1 breast cancers would not have been detected at that screen after the age of 40 years. The percentage of early-stage (DCIS or $<1 \mathrm{~cm}$ invasive) cancers detected with both MRI and mammography screening of $36.6 \%$ 
(41 out of 112) would decrease by $3.6 \%$ (37 out of 112) if mammography was not be performed. Using combined MRI and mammography, $63.4 \%$ of the detected cancers were invasive and $>1 \mathrm{~cm}$, with $0.9 \%$ of these detected by mammography only. To detect one breast cancer missed by MRI, we estimated that 527 screens for the first screening round and 717 screens for subsequent rounds with mammography would be needed.

The contribution of mammography above MRI to screening sensitivity in the 72 BRCA2 mutation carriers was $12.6 \%(P>0.05)$. Additional mammography in BRCA2 mutation carriers also decreased the specificity. Without mammography one-third of breast cancers would not have been detected in BRCA2 mutation carriers aged 40 years and younger, but this proportion was $9.3 \%$ in those older than 40 years. We estimate that the percentage of BRCA2 cancers detected at very early stage (DCIS or invasive $<1 \mathrm{~cm}$ ) with combined MRI and mammography screening of $54.2 \%$ (39 out of 72 ) would decrease to $47.2 \%$ (34 out of 72 ) without mammography. Only 94 screens at first round and 231 screens at subsequent rounds of mammography screening are needed to detect a breast cancer missed by MRI. Without mammography, four advanced-stage cancers (4 out of 72 cancers, 5.6\%) would have been missed in BRCA2 carriers. An advantage of mammography over MRI has been the ability to detect DCIS by visualising microcalcifications. The proportion of DCIS is larger for women with a BRCA2 mutation than for women with a $B R C A 1$ mutation, thus differences in histology distributions in $B R C A$-associated breast cancers may account for our findings (Heijnsdijk et al, 2012). There might also be $B R C A$ mutation-specific differences in tumour phenotypes that also contribute to differences in screen detection. The modest additional value of digital-only mammography to current MRI screening of BRCA1 mutation carriers was recently shown in a retrospective study (Obdeijn et al, 2014). Only 2 (2\%) DCIS of 94 breast cancers were detected by mammography alone, none in women aged below 40 years and no invasive cancers. Importantly, in this retrospective study with recent data MRI screening detected $67 \%$ of the breast cancers detected as DCIS or $<1 \mathrm{~cm}$, considerably more than the $41-44 \%$ published for the Dutch, UK and Canadian studies of our IPD meta-analyses (Rijnsburger et al, 2010; Passaperuma et al, 2012; Evans et al, 2014) or $36.6 \%$ of this IPD meta-analysis.

It could be argued that at the time the studies forming our IPD analyses were conducted, radiologists might not have had extensive experience with breast MRI screening. Most likely, both a learning curve, as expected for any new screening modality, and improved techniques explain the relatively improved MRI sensitivities in more recent studies. A learning curve for MRI screening accuracy in high-risk women was evident for the Canadian study, in particular for DCIS detection (Warner et al, 2011). However, in a previous report in this study population (Phi et al, 2014), the sensitivity of each of MRI and mammography fluctuated over the years, and heterogeneity was evident across different studies possibly masking any potential effect of timeframe (Phi et al, 2014). A cohort study from the Netherlands showed that digital mammography had higher sensitivity compared with studies reporting film mammography (and a transition to digital) (Obdeijn et al, 2014). However, in the Italian HIBCRIT-1 Study, transition from film screen to digital mammography (resulting in screening with roughly equal mix of film screen and digital) did not increase mammography sensitivity in high-risk women (Sardanelli et al, 2011). Newer mammography technologies such as tomosynthesis (3D mammography), which have better screening sensitivity than standard mammography (Houssami et al, 2014), have not yet been compared with MRI screening of $B R C A$ carriers. This lacking evidence in high-risk screening is worthy of research effort but would still imply increased ionising radiation from tomosynthesis (Svahn et al, 2014).
In contrast to benefits of possible earlier breast cancer detection, there are also possible harmful effects of additional mammography as outlined in the Introduction. Two-fold increase in breast cancers in $B R C A 1 / 2$ mutation carriers after exposure to 4 or more radiographs, compared with non-exposure, was significant below age 30 years $(\mathrm{HR}=1.9$ (95\% CI: $1.2-3.0)$, but not at $30-39$ years (Pijpe et al, 2012). Two other studies did not demonstrate tumour induction in BRCA1/2 mutation carriers by screening mammography or low-dose contralateral irradiation from breast-conserving treatment (Pierce et al, 2000; Narod et al, 2006). However, this may have been because of modest follow-up time in these studies, with consideration that latency time for radiation-induced breast cancer is 10-15 years (Travis et al, 2005; Jansen-van der Weide et al, 2010).

From two meta-analyses based on retrospective studies, the estimated cumulative risk of breast cancer by the age of 70 years vary from $57 \%(95 \% \mathrm{CI}: 47-66 \%)$ to $65 \%$ (95\% CI: $44-78)$ in women with a BRCA1 mutation and from $45 \%$ (95\% CI: $31-56 \%$ ) to $49 \%$ (95\% CI: $40-57)$ in women with a BRCA2 mutation (Antoniou et al, 2003; Chen and Parmigiani, 2007). In this IPD meta-analysis, we combined IPD from six prospective studies, making this the largest analysis in the world of prospectively collected screening data on BRCA1/2 mutation carriers, although numbers are modest in some subgroups. We did not observe a significant difference in the risk of breast cancer between $B R C A 1$ and $B R C A 2$ mutation carriers given a relatively small sample of breast cancers in the IPD data set. Although data from six studies could not be included, this only resulted in $\sim 716$ women with $B R C A 1 / 2$ mutations (36 breast cancers) not being included in the IPD (Kuhl et al, 2005, 2010; Lehman et al, 2005, 2007; Hagen et al, 2007; Weinstein et al, 2009). As these studies showed generally similar results for the added value of mammography to MRI, we would not expect their non-inclusion to have substantially altered our estimates.

This work differs from our recent report using the same IPD data (Phi et al, 2014) because the present analyses focus on screening outcomes by BRCA status and age group to determine mammography's contribution. Based on our findings, the additional detection from mammography in BRCA1 mutation carriers who receive MRI screening is minimal, and might not outweigh potential disadvantages (potential cancer induction by radiation, false-positive results). It may be reasonable, on the basis of this collective evidence, to consider potential omission of mammography screening in $B R C A 1$ mutation carriers or to open discussion on its potential omission given its limited contribution. In BRCA2 mutation carriers, the contribution of mammography above MRI is more evident. Different screening recommendations for these two groups of women defined by BRCA mutation status should be considered on the basis of the evidence we report, factoring the estimated contribution of mammography and its potential harms.

\section{ACKNOWLEDGEMENTS}

No specific project funding was received. N Houssami receives a National Breast Cancer Foundation (NBCF Australia) Breast Cancer Research Leader Fellowship.

\section{CONFLICT OF INTEREST}

The following authors reported consulting or advisory roles: Thomas H Helbich (Siemens; Philips); Francesco Sardanelli (Bayer HealthCare including honoraria; Bracco Imaging including funding; IMS-Giotto including funding); Edwin $\mathrm{R}$ van den Heuvel (MSD). The other authors declare no conflict of interest. 


\section{REFERENCES}

Antoniou A, Pharoah PD, Narod S, Risch HA, Eyfjord JE, Hopper JL, Loman N, Olsson H, Johannsson O, Borg A, Pasini B, Radice P, Manoukian S, Eccles DM, Tang N, Olah E, Anton-Culver H, Warner E, Lubinski J, Gronwald J, Gorski B, Tulinius H, Thorlacius S, Eerola H, Nevanlinna H, Syrjakoski K, Kallioniemi OP, Thompson D, Evans C, Peto J, Lalloo F, Evans DG, Easton DF (2003) Average risks of breast and ovarian cancer associated with BRCA1 or BRCA2 mutations detected in case series unselected for family history: a combined analysis of 22 studies. Am J Hum Genet 72(5): 1117-1130.

Chen S, Parmigiani G (2007) Meta-analysis of BRCA1 and BRCA2 penetrance. J Clin Oncol 25(11): 1329-1333.

Evans DG, Kesavan N, Lim Y, Gadde S, Hurley E, Massat NJ, Maxwell AJ, Ingham S, Eeles R, Leach MO. MARIBS GroupHowell A, Duffy SW (2014) MRI breast screening in high-risk women: cancer detection and survival analysis. Breast Cancer Res Treat 145(3): 663-672.

Glasziou P, Houssami N (2011) The evidence base for breast cancer screening. Prev Med 53(3): 100-102.

Hagen AI, Kvistad KA, Maehle L, Holmen MM, Aase H, Styr B, Vabo A, Apold J, Skaane P, Moller P (2007) Sensitivity of MRI versus conventional screening in the diagnosis of BRCA-associated breast cancer in a national prospective series. Breast (Edinburgh, Scotland) 16(4): 367-374.

Heemskerk-Gerritsen BA, Menke-Pluijmers MB, Jager A, Tilanus-Linthorst MM, Koppert LB, Obdeijn IM, van Deurzen CH, Collee JM, Seynaeve C, Hooning MJ (2013) Substantial breast cancer risk reduction and potential survival benefit after bilateral mastectomy when compared with surveillance in healthy BRCA1 and BRCA2 mutation carriers: a prospective analysis. Ann Oncol 24(8): 2029-2035.

Heijnsdijk EA, Warner E, Gilbert FJ, Tilanus-Linthorst MM, Evans G, Causer PA, Eeles RA, Kaas R, Draisma G, Ramsay EA, Warren RM, Hill KA, Hoogerbrugge N, Wasser MN, Bergers E, Oosterwijk JC, Hooning MJ, Rutgers EJ, Klijn JG, Plewes DB, Leach MO, de Koning HJ (2012) Differences in natural history between breast cancers in BRCA1 and BRCA2 mutation carriers and effects of MRI screening-MRISC, MARIBS, and Canadian studies combined. Cancer Epidemiol Biomarkers Prev 21(9): $1458-1468$

Houssami N, Macaskill P, Bernardi D, Caumo F, Pellegrini M, Brunelli S, Tuttobene P, Bricolo P, Fanto C, Valentini M, Ciatto S (2014) Breast screening using $2 \mathrm{D}$-mammography or integrating digital breast tomosynthesis (3D-mammography) for single-reading or double-reading - evidence to guide future screening strategies. Eur J Cancer (Oxford, England: 1990) 50(10): 1799-1807.

Jansen-van der Weide MC, Greuter MJ, Jansen L, Oosterwijk JC, Pijnappel RM, de Bock GH (2010) Exposure to low-dose radiation and the risk of breast cancer among women with a familial or genetic predisposition: a meta-analysis". Eur Radiol 20(11): 2547-2556.

Kuhl C, Weigel S, Schrading S, Arand B, Bieling H, Konig R, Tombach B, Leutner C, Rieber-Brambs A, Nordhoff D, Heindel W, Reiser M, Schild HH (2010) Prospective multicenter cohort study to refine management recommendations for women at elevated familial risk of breast cancer: the EVA trial. J Clin Oncol 28(9): 1450-1457.

Kuhl CK, Schrading S, Leutner CC, Morakkabati-Spitz N, Wardelmann E, Fimmers R, Kuhn W, Schild HH (2005) Mammography, breast ultrasound, and magnetic resonance imaging for surveillance of women at high familial risk for breast cancer. J Clin Oncol 23(33): 8469-8476.

Kurian AW, Sigal BM, Plevritis SK (2010) Survival analysis of cancer risk reduction strategies for BRCA1/2 mutation carriers. J Clin Oncol 28(2): 222-231.

Leach MO, Boggis CR, Dixon AK, Easton DF, Eeles RA, Evans DG, Gilbert FJ, Griebsch I, Hoff RJ, Kessar P, Lakhani SR, Moss SM, Nerurkar A, Padhani AR, Pointon LJ, Thompson D, Warren RM. MARIBS Study Group (2005) Screening with magnetic resonance imaging and mammography of a UK population at high familial risk of breast cancer: a prospective multicentre cohort study (MARIBS). Lancet 365(9473): 1769-1778.

Lehman CD, Blume JD, Weatherall P, Thickman D, Hylton N, Warner E, Pisano E, Schnitt SJ, Gatsonis C, Schnall M, DeAngelis GA, Stomper P, Rosen EL, O'Loughlin M, Harms S, Bluemke DA. International Breast MRI Consortium Working Group (2005) Screening women at high risk for breast cancer with mammography and magnetic resonance imaging. Cancer 103(9): 1898-1905.
Lehman CD, Isaacs C, Schnall MD, Pisano ED, Ascher SM, Weatherall PT, Bluemke DA, Bowen DJ, Marcom PK, Armstrong DK, Domchek SM, Tomlinson G, Skates SJ, Gatsonis C (2007) Cancer yield of mammography, MR, and US in high-risk women: prospective multiinstitution breast cancer screening study. Radiology 244(2): 381-388.

Lord SJ, Lei W, Craft P, Cawson JN, Morris I, Walleser S, Griffiths A, Parker S, Houssami N (2007) A systematic review of the effectiveness of magnetic resonance imaging (MRI) as an addition to mammography and ultrasound in screening young women at high risk of breast cancer. Eur J Cancer (Oxford, England: 1990) 43(13): 1905-1917.

Mann RM, Kuhl CK, Kinkel K, Boetes C (2008) Breast MRI: guidelines from the European Society of Breast Imaging. Eur Radiol 18(7): 13071318.

Narod SA, Lubinski J, Ghadirian P, Lynch HT, Moller P, Foulkes WD, Rosen B, Kim-Sing C, Isaacs C, Domchek S, Sun P. Hereditary Breast Cancer Clinical Study Group (2006) Screening mammography and risk of breast cancer in BRCA1 and BRCA2 mutation carriers: a case-control study. Lancet Oncol 7(5): 402-406.

NICE (2013) CG 164 Familial breast cancer: NICE Guidance. Available at http://guidance.nice.org.uk/CG164/NICEGuidance/pdf/English (last accessed 23 September 2013).

Obdeijn IM, Winter-Warnars GA, Mann RM, Hooning MJ, Hunink MG, Tilanus-Linthorst MM (2014) Should we screen BRCA1 mutation carriers only with MRI? A multicenter study. Breast Cancer Res Treat 144(3): 577-582.

Passaperuma K, Warner E, Causer PA, Hill KA, Messner S, Wong JW, Jong RA, Wright FC, Yaffe MJ, Ramsay EA, Balasingham S, Verity L, Eisen A, Curpen B, Shumak R, Plewes DB, Narod SA (2012) Long-term results of screening with magnetic resonance imaging in women with BRCA mutations. Br J Cancer 107(1): 24-30.

Phi X, Houssami N, Obdeijn I, Warner E, Sardanelli F, Leach MO, Riedl CC, Trop I, Tilanus-Linthorst MM, Mandel R, Santoro F, Kwan-Lim G, Helbich TH, de Koning HJ, Van den Heuvel ER, de Bock GH (2014) Magnetic resonance imaging improves breast screening sensitivity in BRCA mutation carriers age $>I=50$ years: evidence from an individual patient data meta-analysis. J Clin Oncol 33(4): 349-356.

Pierce LJ, Strawderman M, Narod SA, Oliviotto I, Eisen A, Dawson L, Gaffney D, Solin LJ, Nixon A, Garber J, Berg C, Isaacs C, Heimann R, Olopade OI, Haffty B, Weber BL (2000) Effect of radiotherapy after breast-conserving treatment in women with breast cancer and germline BRCA1/2 mutations. J Clin Oncol 18(19): 3360-3369.

Pijpe A, Andrieu N, Easton DF, Kesminiene A, Cardis E, Nogues C, GauthierVillars M, Lasset C, Fricker JP, Peock S, Frost D, Evans DG, Eeles RA, Paterson J, Manders P, van Asperen CJ, Ausems MG, Meijers-Heijboer H, Thierry-Chef I, Hauptmann M, Goldgar D, Rookus MA, van Leeuwen FE. GENEPSO, EMBRACE, HEBON (2012) Exposure to diagnostic radiation and risk of breast cancer among carriers of BRCA1/2 mutations: retrospective cohort study (GENE-RAD-RISK). BMJ (Clin Res Ed.) 345: e5660.

Powell SN, Kachnic LA (2003) Roles of BRCA1 and BRCA2 in homologous recombination, DNA replication fidelity and the cellular response to ionizing radiation. Oncogene 22(37): 5784-5791.

Riedl CC, Luft N, Bernhart C, Weber M, Bernathova M, Tea MK, Rudas M, Singer CF, Helbich TH (2015) Triple-modality screening trial for familial breast cancer underlines the importance of magnetic resonance imaging and questions the role of mammography and ultrasound regardless of patient mutation status, age, and breast density. J Clin Oncol 33(10): $1128-1135$

Rijnsburger AJ, Obdeijn IM, Kaas R, Tilanus-Linthorst MM, Boetes C, Loo CE, Wasser MN, Bergers E, Kok T, Muller SH, Peterse H, Tollenaar RA, Hoogerbrugge N, Meijer S, Bartels CC, Seynaeve C, Hooning MJ, Kriege M, Schmitz PI, Oosterwijk JC, de Koning HJ, Rutgers EJ, Klijn JG (2010) BRCA1-associated breast cancers present differently from BRCA2associated and familial cases: long-term follow-up of the Dutch MRISC Screening Study. J Clin Oncol 28(36): 5265-5273.

Sardanelli F, Boetes C, Borisch B, Decker T, Federico M, Gilbert FJ, Helbich T, Heywang-Kobrunner SH, Kaiser WA, Kerin MJ, Mansel RE, Marotti L, Martincich L, Mauriac L, Meijers-Heijboer H, Orecchia R, Panizza P, Ponti A, Purushotham AD, Regitnig P, Del Turco MR, Thibault F, Wilson R (2010) Magnetic resonance imaging of the breast: recommendations from the EUSOMA working group. Eur J Cancer (Oxford, England: 1990) 46(8): 1296-1316. 
Sardanelli F, Podo F, Santoro F, Manoukian S, Bergonzi S, Trecate G, Vergnaghi D, Federico M, Cortesi L, Corcione S, Morassut S, Di Maggio C, Cilotti A, Martincich L, Calabrese M, Zuiani C, Preda L, Bonanni B, Carbonaro LA, Contegiacomo A, Panizza P, Di Cesare E, Savarese A, Crecco M, Turchetti D, Tonutti M, Belli P, Maschio AD. High Breast Cancer Risk Italian 1 (HIBCRIT-1) Study (2011) Multicenter surveillance of women at high genetic breast cancer risk using mammography, ultrasonography, and contrast-enhanced magnetic resonance imaging (the High Breast Cancer Risk Italian 1 Study): final results. Invest Radiol 46(2): 94-105.

Svahn TM, Houssami N, Sechopoulos I, Mattsson S (2014) Review of radiation dose estimates in digital breast tomosynthesis relative to those in two-view full-field digital mammography. Breast (Edinburgh, Scotland) 24(2): 93-99.

Travis LB, Hill D, Dores GM, Gospodarowicz M, van Leeuwen FE, Holowaty E, Glimelius B, Andersson M, Pukkala E, Lynch CF, Pee D, Smith SA, Van't Veer MB, Joensuu T, Storm H, Stovall M, Boice Jr JD, Gilbert E, Gail MH (2005) Cumulative absolute breast cancer risk for young women treated for Hodgkin lymphoma. J Natl Cancer Inst 97(19): 1428-1437.

Trop I, Lalonde L, Mayrand MH, David J, Larouche N, Provencher D (2010) Multimodality breast cancer screening in women with a familial or genetic predisposition. Curr Oncol (Toronto, ON) 17(3): 28-36.
Warner E, Causer PA, Wong JW, Wright FC, Jong RA, Hill KA, Messner SJ, Yaffe MJ, Narod SA, Plewes DB (2011) Improvement in DCIS detection rates by MRI over time in a high-risk breast screening study. Breast $J$ 17(1): 9-17.

Warner E, Messersmith H, Causer P, Eisen A, Shumak R, Plewes D (2008) Systematic review: using magnetic resonance imaging to screen women at high risk for breast cancer. Ann Intern Med 148(9): 671-679.

Weinstein SP, Localio AR, Conant EF, Rosen M, Thomas KM, Schnall MD (2009) Multimodality screening of high-risk women: a prospective cohort study. J Clin Oncol 27(36): 6124-6128.

Zonderland HM, van Vegchel T, van Asperen CJ, Benraadt J, de Bock GH, den Heeten GJ, Rutgers EJT, Smit-Hoeksma GM, Strobbe LJA, van Tienhoven G, Tuut MK, Westenend PJ, Wittenberg J (2012) 13-02-2012-last update, Richtlijn mammacarcinoom (Breast Cancer National Guideline). Available at http://richtlijnendatabase.nl/en/richtlijn/ breast_cancer/screening.html (last accessed 10 February 2016).

This work is published under the standard license to publish agreement. After 12 months the work will become freely available and the license terms will switch to a Creative Commons AttributionNonCommercial-Share Alike 4.0 Unported License. 